\title{
Crescimento microbiano em produtos à base de peito de frango durante simulação da cadeia de abastecimento
}

\author{
Microbial growth in chicken breast products during supply chain simulation
}

Liane Aldrighi GALARZ ${ }^{1}$, Gustavo Graciano FONSECA${ }^{1}$, Carlos PRENTICE-HERNÁNDEZ ${ }^{\text {* }}$

\section{Resumo}

A presença de microrganismos em produtos alimentícios durante produção, armazenamento, transporte e embalagem é inevitável. Sendo assim, conhecer o comportamento do crescimento microbiano é muito importante para a segurança alimentar e estimativa da vida útil. Neste trabalho foi simulada a cadeia de abastecimento de peitos de frangos cru, salgado e cozido durante 20 dias a $-18 \pm 0,5^{\circ} \mathrm{C}($ simulação da expedição industrial no Brasil e transporte por navio até a Europa) e, após o descongelamento, 21 dias a $4 \pm 0,5^{\circ} \mathrm{C}$ ( $\operatorname{simulação~da~vida~útil~}$ em supermercado). Os produtos foram analisados quanto a Pseudomonas spp., Salmonella spp., Listeria monocytogenes, Staphylococcus spp. e microrganismos viáveis totais (mesófilos e psicrotróficos). As análises de contagem em placas foram seguidas por testes bioquímicos clássicos para a confirmação de colônias típicas. Em nenhuma das amostras foi detectada a presença de Salmonella spp. ou de Listeria monocytogenes. Em termos de contagem de colônias viáveis totais, durante os primeiros 20 dias $\left(\mathrm{a}-18^{\circ} \mathrm{C}\right)$ a presença de microrganismos se manteve estável em baixos níveis de detecção. Depois do descongelamento, curvas de crescimento microbiano foram observadas. De acordo com os parâmetros microbiológicos de segurança, tempos entre 9 e 11 dias a $4{ }^{\circ} \mathrm{C}$ mostraram-se como os limites para garantir a qualidade destes produtos.

Palavras-chave: filé de frango; cadeia de suprimento; microbiologia; simulação; vida útil.

\begin{abstract}
The presence of the microbial organisms in food products during the production, storage, transport, and packaging is unavoidable. Therefore, the knowledge of the microbial growth behavior is very important for the food safety and shelf life assessment. In this work, a chicken supply chain was simulated for raw, salted, and cooked chicken breasts for 20 days at $-18 \pm 0.5^{\circ} \mathrm{C}$ (simulation of industry expedition in Brazil and transport by ship to Europe) and for defrosted chicken breasts for 21 days at $4 \pm 0.5^{\circ} \mathrm{C}$ ( $\operatorname{simulation}$ of the shelf life in supermarket). The products were analyzed for Pseudomonas spp., Salmonella spp., Lysteria monocytogenes, Staphylococcus spp. and total viable counts (mesophilic and psicrotrophic microorganisms). The counting plate analyses were followed by classical biochemical tests for typical colonies confirmation. None of the samples was positive for Salmonella spp. and Lysteria monocytogenes. In terms of total viable colonies counting, during the first 20 days $\left(-18^{\circ} \mathrm{C}\right)$, the presence of microorganisms was kept stable at low levels of detection. After defrosting, microbial growth curves were observed. According to the safety parameters, 9 to 11 days at $4{ }^{\circ} \mathrm{C}$ proved the best time limit to guarantee the quality of those products.

Keywords: chicken breast; supply chain; microbiology; simulation; shelf life.
\end{abstract}

\section{Introdução}

O consumo de produtos alimentícios refrigerados e congelados está crescendo acima da média dos últimos anos devido às mudanças na sociedade (VALERIANO et al., 2003). Sendo assim, a segurança e o controle alimentares são de grande preocupação para os consumidores. O reforço da confiança em produtos alimentícios refrigerados e congelados, especialmente no que diz respeito aos aspectos da cadeia de abastecimento, é de alta prioridade para todos os envolvidos na fabricação, comércio, logística e distribuição de alimentos. Isto porque, desde janeiro de 2005, o Regulamento 178/2002/EC na Lei Geral de Alimentos exige a rastreabilidade da cadeia alimentar em todos os seus estágios (UNIÃO EUROPEIA, 2002). Esta diretriz orientadora forçará a introdução de mecanismos de segurança e controles para os gêneros alimentícios cujo destino é a exportação.
Os alimentos podem servir de veículo e/ou substrato para a multiplicação de diversos microrganismos, muitas vezes patogênicos, capazes de produzir toxinas, podendo assim causar risco à saúde do consumidor quando ingeridos (BRYAN, 1998; CANSIAN et al., 2005; GONÇALVES, 1998; PARDI et al., 1995). A contaminação de frango refrigerado e congelado é alta em comparação a outros alimentos (MEAD, 1989; PINI; GILBERT, 1993; UBOLDI-EIROA, 1990; UYTTENDALE et al., 1997). Desta forma, o presente trabalho objetivou avaliar o crescimento microbiano em peito de frango, de grande demanda no mercado norte-americano, através da simulação da cadeia de abastecimento, ou seja, pelo acompanhamento da contaminação microbiana através do tempo, a fim de verificar a relação dos diferentes tratamentos que poderiam ser utilizados 
pela indústria para aumentar a vida útil do produto sem fornecer riscos ao consumidor, a parte final da cadeia.

\section{Material e métodos}

\subsection{Amostras e microrganismos}

As amostras avaliadas foram: filé de peito de frango cru (PI), filé de peito de frango temperado com $\mathrm{NaCl}$ (PS) e filé de peito de frango cozido (PC). As amostras foram provenientes de uma grande indústria processadora de frango localizada no Estado de Santa Catarina, Brasil. Estas foram transportadas congeladas a $-18 \pm 0,5^{\circ} \mathrm{C}$, em período inferior a 24 horas, por veículos da própria indústria até o Laboratório de Tecnologia de Alimentos da FURG, Rio Grande - RS, onde foram realizadas todas as análises. Assim que recebidas, foram divididas em porções, acondicionadas em sacos de polietileno estéreis e imediatamente rearmazenadas a $-18 \pm 0,5{ }^{\circ} \mathrm{C}$, mantendo-se sempre condições de máxima assepsia. Os diversos cortes de frango procederam de lotes recém-congelados (tempo máximo mantido congelado na indústria inferior a 24 horas), a fim de se evitar qualquer interferência sobre o estudo. A Tabela 1 mostra os microrganismos que foram avaliados em função das diferentes características das amostras consideradas.

\subsection{Composição proximal}

A composição proximal foi determinada conforme descrito pela AOAC (1995). A umidade foi medida por perda de peso da amostra em estufa aquecida a $105 \pm 1{ }^{\circ} \mathrm{C}$, até o peso constante. A proteína bruta foi determinada mediante a determinação do nitrogênio total, pelo método micro Kjeldahl, e conversão em proteína multiplicando o valor obtido pelo fator 6,25. Os lipídios foram extraídos a quente, com extrator de Soxhlet, utilizando éter de petróleo como solvente extrator. As cinzas foram expressas como a porcentagem de resíduo remanescente após oxidação.

\subsection{Determinação do pH e de $\mathrm{NaCl}$}

$\mathrm{O}$ pH foi determinado pela utilização de potenciômetro digital (ANALION Mod. PM 608) a partir do músculo de frango homogeneizado em água destilada, na proporção 1:1. O teor de $\mathrm{NaCl}$ das amostras de Peito Salgado (PS) foi determinado pelo método de Mohr (AOAC, 1995).

\subsection{Simulação da cadeia de suprimento de frango}

A cadeia de suprimento do frango brasileiro que é exportado para a Europa foi simulada em laboratório. Consideraram-se as condições reais, desde o transporte de navio, que é em média de 20 dias a $-18 \pm 0,5^{\circ} \mathrm{C}$, a partir do porto de Itajaí - SC, até os principais portos europeus, bem como a temperatura em que o produto é mantido exposto ao

Tabela 1. Produtos de frango e respectivos microrganismos analisados.

\begin{tabular}{lll}
\hline \multicolumn{1}{c}{$\begin{array}{c}\text { Filé de peito } \\
\text { cru }\end{array}$} & \multicolumn{1}{c}{$\begin{array}{c}\text { Filé de peito } \\
\text { cozido }\end{array}$} & \multicolumn{1}{c}{$\begin{array}{c}\text { Filé de peito } \\
\text { temperado com } \mathrm{NaCl}\end{array}$} \\
\hline Pseudomonas spp. & Pseudomonas spp. & Pseudomonas spp. \\
Salmonella spp. & Listeria monocytogenes & Salmonella spp. \\
Aeróbios $^{\mathrm{a}}$ & & Aeróbios $^{\mathrm{a}}$ \\
& & Staphylococcus spp. \\
\hline
\end{tabular}

${ }^{a}$ Aeróbios mesófilos e psicrotróficos. Fonte: Davies e Board (1998), Barbut (2002), Franco e Landgraf (2005) e Jay (2005). consumidor, que geralmente oscila em torno de $4 \pm 0,5{ }^{\circ} \mathrm{C}$. $\mathrm{Na}$ simulação, os produtos foram mantidos a $-18 \pm 0,5^{\circ} \mathrm{C}$ por 20 dias, sendo que a cada 5 dias uma amostra era coletada para a realização das análises microbianas. Após este período, as amostras não analisadas foram transferidas para refrigerador a $4 \pm 0,5{ }^{\circ} \mathrm{C}$, com o objetivo de simular as condições de armazenamento em estabelecimentos comerciais. Nesta etapa os produtos foram analisados a cada 3 dias, até atingir-se a fase estacionária de crescimento microbiano.

\subsection{Análise microbianas}

As análises microbianas foram realizadas em duplicatas para cada produto. A escolha dos microrganismos para este estudo foi baseada na literatura (DAVIES; BOARD, 1998; BARBUT, 2002; FRANCO; LANDGRAF, 2005; JAY, 2005). Foram analisadas bactérias aeróbias mesófilas e psicrotróficas, Pseudomonas spp., Staphylococcus spp., Listeria monocytogenes e Salmonella spp. Quando detectáveis, placas com contagens entre 25 e 250 colônias foram selecionadas para o cálculo das Unidades Formadoras de Colônias (UFC).

\section{Aeróbios mesófilos totais}

Foi transferido $1 \mathrm{~mL}$ de sucessivas diluições para placas de Petri estéreis. A seguir, ágar padrão para contagem (Acumedia Manufacturers, Inc., Baltimore, MD, Estados Unidos), a aproximadamente $45^{\circ} \mathrm{C}$, foi adicionado à medida que suave agitação era realizada para homogeneizar a amostra e o ágar. Foram preparadas duas placas para cada diluição. As placas foram incubadas invertidas a $35^{\circ} \mathrm{C}$ por 48 horas.

\section{Aeróbios psicrotróficos totais}

Foram espalhados, com alça de Drigalsky, 0,1 mL de cada diluição apropriada, em placas de Petri contendo ágar padrão para contagem (Acumedia), em duplicata. A seguir, as placas foram incubadas a $20^{\circ} \mathrm{C}$ por 72 horas.

\section{Staphyloccoccus spp.}

Foram utilizadas placas de Petri contendo ágar Baird-Parker (Acumedia) adicionado de telurito de potássio e gema de ovo. $\mathrm{Na}$ superfície seca das placas, foi adicionado 0,1 ou $1 \mathrm{~mL}$ (sendo 0,$3 ; 0,3 ; 0,3$ e $0,1 \mathrm{~mL}$ distribuídos em diferentes placas) de cada diluição selecionada. As placas foram incubadas a $35^{\circ} \mathrm{C}$ por 48 horas (BRASIL, 2003).

\section{Pseudomonas spp.}

Foi semeado, em duplicata, $0,1 \mathrm{~mL}$ de cada diluição selecionada em placas de Petri contendo ágar para isolamento de Pseudomonas (Acumedia) adicionado de glicerol. As placas foram incubadas a $25^{\circ} \mathrm{C}$ por 48 horas (STANBRIDGE; BOARD, 1994).

\section{Listeria monocytogenes}

Foram homogeneizados $25 \mathrm{~g}$ de cada amostra em $225 \mathrm{~mL}$ do Caldo Universidade de Vermont - UVM (Oxoid, Basingstoke, Reino Unido) e incubados a $30^{\circ} \mathrm{C}$ por 24 horas. Após delicada 
agitação do frasco de enriquecimento seletivo primário, $0,1 \mathrm{~mL}$ do caldo UVM foi transferido para um tubo com $10,0 \mathrm{~mL}$ de caldo Fraser (Acumedia) e incubado a $35^{\circ} \mathrm{C}$ por $24-40$ horas. Quando observada a ocorrência de escurecimento no caldo Fraser, devido à reação de hidrólise da esculina, as amostras foram submetidas ao plaqueamento, sendo descartadas as amostras negativas. As placas de ágar Oxford Modificado MOX (Oxoid) foram incubadas a $35^{\circ} \mathrm{C}$ e a presença de colônias típicas observada após 24 e 48 horas de incubação. Foram selecionadas pelo menos 5 colônias típicas de cada placa, para confirmação. Cada uma destas colônias foi estriada em placas de Agar Tripticase de Soja suplementado com 0,6\% de extrato de levedura - TSA-YE (Acumedia), para purificação, e incubada a $30{ }^{\circ} \mathrm{C}$ por $24-48$ horas. As colônias foram observadas sob luz oblíqua e selecionadas as colônias azuladas típicas para a realização das provas de confirmação. Com uma alça de inoculação, cada colônia foi transferida para um tubo de TSAYE inclinado e um tubo de Caldo Tripticase de Soja 0,6\% de extrato de levedura - TSB-YE (Acumedia). Os tubos foram incubados a $30^{\circ} \mathrm{C}$ por 24 horas. Utilizou-se a cultura em ágar e o caldo para a realização das provas bioquímicas: teste da catalase, teste de motilidade, teste de nitrato, reação em Ágar Tríplice Açúcar Ferro - TSI (Acumedia).

\section{Salmonella spp.}

Foram pesados $25 \pm 0,2 \mathrm{~g}$ da amostra e adicionados $225 \mathrm{~mL}$ de solução salina peptonada $1 \%$ tamponada. A seguir, foi realizada homogeneização por aproximadamente 60 segundos em stomacher e as amostras foram deixadas por 1 hora em temperatura ambiente. As alíquotas das amostras preparadas foram incubadas a $36 \pm 1{ }^{\circ} \mathrm{C}$ por, no mínimo, 16 horas e não mais que 20 horas, para o pré-enriquecimento. Após este período, alíquotas de $0,1 \mathrm{~mL}$ foram transferidas para $10 \mathrm{~mL}$ de caldo Rappaport-Vassiliardis - RP (Acumedia) e para $10 \mathrm{~mL}$ de caldo Selenito-Cistina - SC (Acumedia) para o enriquecimento seletivo, sendo incubadas a $41 \pm 0,5^{\circ} \mathrm{C}$, em banho-maria, com agitação contínua de água, por 24 a 30 horas. De cada tubo, procedeu-se o isolamento de colônias típicas em ágar XLD, BPLS e HE (Difco Laboratories, Detroit, MI, Estados Unidos) por meio de estria com incubação a $36 \pm 1^{\circ} \mathrm{C}$ por 18 a 24 horas. Colônias suspeitas foram estriadas em ágar inclinado Triple Sugar Iron - TSI (Merck, São Paulo - SP, Brasil) e Lysine Iron Agar - LIA (Merck) e incubadas por 24 horas a $35^{\circ} \mathrm{C}$. Os isolados que apresentaram reações características de Salmonella spp. foram submetidos à identificação bioquímica com os seguintes testes: produção de urease, motilidade em meio SIM - Syulphide Indol Motility (Merck), produção de $\mathrm{H}_{2} \mathrm{~S}$, utilização de citrato, produção de indol, fermentação do malonato e produção de fenilalanina. Os isolados que apresentaram resultado característico para Salmonella spp. nos testes bioquímicos foram avaliados por teste sorológico, com antissoro polivalente "O" (Difco) e reação de Voges-Proskauer, com caldo Vermelho de Metila - Voges-Proskauer (Difco).

\subsection{Determinação de parâmetros de crescimento microbiano}

Os cálculos para a determinação de Unidades Formadoras de Colônias por grama de amostra (UFC. $\mathrm{g}^{-1}$ ) foram realizados em função do número de colônias contadas e diluição inoculada (BRASIL, 2003). A velocidade máxima específica de crescimento $\left(\mu_{\text {max }}\right)$ foi determinada como o declive da região linear entre o ln da contagem microbiana versus o tempo de crescimento. A contagem máxima foi o logaritmo do mais alto valor de contagem microbiana. A vida útil do produto foi o tempo levado até que cada microrganismo atingisse a contagem máxima estabelecida como limite de segurança.

\section{Resultados e discussão}

\subsection{Composição proximal}

A Tabela 2 apresenta os valores de composição proximal das amostras de filé de peito de frango cozido (PC), cru in natura (PI) e temperado com $\mathrm{NaCl}$ (PS) obtidos neste estudo, os indicados pela indústria fornecedora dos produtos e aqueles encontrados na literatura. Os conteúdos de umidade, proteínas, lipídios e cinzas determinados neste trabalho mostraram-se dentro ou muito próximo da faixa de valores indicada pela indústria e literatura.

Foram reportados para filé de peito de frango valores de 73,8 a $75,8 \%$ de umidade, 21,5 a $23,7 \%$ de proteínas, 0,9 a $1,3 \%$ de lipídios e 0,9 a 1,2\% de cinzas (NUNES, 2003; VIEIRA et al., 2007; ROÇA, 2008). O teor de umidade determinado para PI foi baixo quando comparado com os dados reportados acima e com os determinados pelo fornecedor das amostras. O inverso ocorreu com lipídios, cujo valor determinado foi superior ao reportado. É possível que no momento do descongelamento,

Tabela 2. Composição proximal, pH e cloretos das amostras de frango (média \pm desvio padrão).

\begin{tabular}{cccccccc}
\hline Amostra & Umidade (\%) & Proteínas (\%) & Lipídios (\%) & Cinzas (\%) & $\mathrm{pH}$ & Cloretos (\%) & Referência \\
\hline PC & $64,6 \pm 0,2$ & $30,8 \pm 3,3$ & $2,6 \pm 0,2$ & $1,1 \pm 0,0$ & 6,11 & Este estudo \\
PI & $72,2 \pm 0,4$ & $23,7 \pm 0,8$ & $2,6 \pm 0,2$ & $1,1 \pm 0,0$ & 5,98 & Este estudo \\
PS & $74,0 \pm 0,3$ & $22,1 \pm 0,2$ & $1,0 \pm 0,1$ & $2,3 \pm 0,2$ & 5,87 & $1,6 \pm 0,1$ & Este estudo \\
PC & $66-70$ & $27-31$ & $\leq 3$ & $1,6-3,5$ & $6,0-6,5$ & - & Fornecedor \\
PI & $73,0-76,5$ & $22-24$ & $0,2-2,5$ & $1-2$ & $5,8-6,8$ & - & Fornecedor \\
PS & $72,5-75,5$ & $22-24$ & $0,2-2,5$ & $1,6-3,5$ & $5,8-6,8$ & $1,2-1,8$ & Fornecedor \\
PC & $61,7-70,0$ & $27,9-35,7$ & $1,1-3,2$ & $0,7-1,3$ & $6,1-6,2$ & - & A \\
PI & $73,8-75,8$ & $21,5-23,7$ & $0,9-1,3$ & $0,9-1,2$ & $5,8-6,0$ & B \\
PS & - & - & - & - & 5,86 & $4 \%$ & C \\
\hline
\end{tabular}

PC = filé de peito de frango cozido; PI = filé de peito de frango cru; PS = filé de peito de frango temperado com NaCl; A: Fletcher et al. (2000) e Vieira et al. (2007); B: Porto et al. (2000), Nunes (2003), Vieira et al. (2007) e Roça (2008); C: Porto et al. (2000). 
anterior à pesagem da amostra, tenha havido uma excessiva exsudação. Assim, a umidade pode ter diminuído e concentrado os outros componentes (VARNAM; SUTHERLAND, 1995).

Uma relação inversamente proporcional entre umidade e lipídios foi previamente demonstrada (KINSELLA et al., 1977; MAIA; RODRIGUEZ-AMAYA, 1992; MAIA; RODRIGUEZAMAYA; FRANCO, 1994; OLIVEIRA, 1999), o que também pode ser verificado para PI. Neste trabalho foi encontrado menor valor de umidade e maior de lipídios que os citados por Nunes (2003), Vieira et al. (2007) e Roça (2008). Desta forma, pode ter ocorrido exsudação durante o descongelamento e, sendo os lipídios apolares, estes não seriam carreados juntamente com a água (polar), pois são insolúveis nela (FENNEMA, 1992).

Na Tabela 2, foi verificado que o PC analisado apresentou teor de umidade inferior ao do PI e PS, enquanto que a porcentagem proteica foi superior. Isto se deve ao fato de que carnes cozidas ou assadas perdem água durante o preparo, o que, consequentemente, aumenta o teor dos outros componentes, como lipídios e proteínas (ROÇA, 2008). As proteínas foram os componentes com mais expressiva relação inversa ao teor de umidade. Isto, talvez, por serem os constituintes em maior porcentagem, excluindo a água. Os teores determinados para PC concordam com dados de literatura para peito de frango cozido por diferentes métodos, sendo eles: 61,7 a 70,0\% de umidade; 27,9 a $35,7 \%$ de proteínas; 1,1 a 3,2\% de gordura; e 0,7 a $1,3 \%$ de cinzas (VIEIRA et al., 2007).

O PS apresentou valor de cinzas superior ao de PC e PI, fato que é entendido pelo fato de $\mathrm{PS}$ possuir adição de $\mathrm{NaCl}$ no seu processamento. Os teores de umidade, proteínas, lipídios e cinzas concordaram com os determinados pela indústria fornecedora. Os valores também se assemelham aos de peito de frango cru (exceto cinzas).

\section{$3.2 p H$}

Os valores de $\mathrm{pH}$ obtidos foram próximos para os três produtos e dentro da faixa indicada pelo fornecedor (Tabela 2). $\mathrm{O}$ valor de $\mathrm{pH}$ do PI corrobora, também, com os da literatura, na qual se encontrou pH de 6,0 (PORTO et al., 2000); 5,96; 5,8 - 5,9; e 5,9 $\pm 0,1$ (NUNES, 2003) para produtos deste tipo. Porto et al. (2000) determinaram $\mathrm{pH}$ de 5,86 em filés de peito de frango marinados com $4 \%$ de $\mathrm{NaCl}$, valor semelhante ao do PS. O valor de $\mathrm{pH}$ um pouco mais alto determinado no PC demonstrou-se próprio, uma vez que concordou com a faixa indicada pelo fornecedor e ainda com dados de literatura, na qual se encontrou faixa de $\mathrm{pH}$ 6,09 - 6,21 para diferentes amostras de peito de frango cozido (FLETCHER; QIAO; $\mathrm{SMITH}, 2000$ ). Tais valores indicam uma carne de boa qualidade e que poderá ter alta durabilidade. Ocorrido o abate, o $\mathrm{pH}$ da carne de frango diminui devido à formação ácida, sendo que a carne de peito deve apresentar pH final entre 5,7 e 5,9. (VENTURINI; SARCINELLI; SILVA, 2007).

\section{$3.3 \mathrm{NaCl}$}

O conteúdo de $\mathrm{NaCl}$ de 1,6\% das amostras de filé de peito de frango temperado apresentou-se na faixa indicada pelo fornecedor (Tabela 2). O NaCl realça o sabor da carne, sendo este o principal objetivo de sua adição no PS. Entretanto, também atua como agente antimicrobiano e higroscópico, contribuindo para a retenção das moléculas de água devido ao aumento da força iônica (GUAJARDO; JARAMILLO, 1995; PORTO et al., 2000), o que proporciona maior rendimento e melhora consideravelmente a textura (FRONING; SACKETT, 1985).

\subsection{Simulação da cadeia de suprimento de frango}

\section{Fase congelada}

O congelamento é um método utilizado para prolongar a vida útil de produtos alimentícios por semanas ou meses. Neste trabalho, observou-se que as contagens de bactérias aeróbias mesófilas e psicrotróficas, Pseudomonas spp. e Staphylococcus spp., mantiveram-se praticamente constantes, com pouca oscilação, durante os 20 dias em que os produtos permaneceram congelados. Enquanto congelada, a água não está disponível e a maioria dos microrganismos não pode crescer (BARBUT, 2002). As concentrações microbianas determinadas neste período foram baixas, podendo-se concluir que houve boas condições higiênicosanitárias no processamento dos produtos, aliado ao fato de que algumas espécies microbianas têm morte súbita após o congelamento (FRANCO; LANDGRAF, 2005; JAY, 2005).

A proporção de células sobreviventes após o congelamento diminui com o tempo (JAY, 2005), contudo, não foi verificada diminuição na carga microbiana, provavelmente por que 20 dias é tempo insuficiente para tal observação. Foi constatada ausência de Listeria monocytogenes e Salmonella spp., no mesmo período, em todos produtos analisados. Este resultado confirma, ainda, as ideais condições de sanidade no processamento dos produtos uma vez que, embora a proporção de células sobreviventes após o congelamento diminua com o tempo, não há eliminação total (JAY, 2005).

\section{Fase refrigerada}

A legislação federal estabelece para carnes de ave resfriadas ausência de Salmonella spp. em $25 \mathrm{~g}$. Nos produtos de frango analisados (PI, PS), Salmonella spp. não foi evidenciada. Tal resultado confirma a qualidade microbiana dos produtos, pois a ausência de Salmonella nas amostras atesta para condições higiênico-sanitárias satisfatórias (SILVA JUNIOR, 2001). Os resultados mostraram-se de acordo com Mesquita et al. (2006), que não detectaram Salmonella spp. em frango in natura, e com Porto et al. (2000), em peito de frango in natura e marinado (4\% de $\mathrm{NaCl}$ ) durante 0,6 e 11 dias de armazenagem a $5{ }^{\circ} \mathrm{C}$.

A bactéria Listeria monocytogenes é um patógeno psicrotrófico transportado por alimentos, que pode causar sérias doenças em humanos (FARBER; PETERKIN, 1991; RYSER; MARTH, 1991; SCHWAB; EDELWEISS, 2003). Pode crescer numa temperatura mínima média de $1{ }^{\circ} \mathrm{C}$, significando que pode desenvolver-se em carne refrigerada (MURIANA, 1996; PELISSER, 2001). As amostras de filé de peito cozido de frango (PC) analisadas apresentaram ausência de Listeria monocytogenes durante os 21 dias mantidos a $4{ }^{\circ} \mathrm{C}$, atestando segurança do produto quanto à listeriose. A Listeria monocytogenes é um contaminante comum em carne de frango 
crua, e cerca de $60 \%$ das carcaças podem conduzir o organismo em baixo número, mas a bactéria é sensível ao calor e destruída por processos normais de cozimento. Assim, a determinação desta bactéria em peito de frango cozido pode ser resultado de contaminação cruzada, conforme se tem reportado que nuggets de aves cozidos e aves cozidas resfriadas foram implicados em esporádicos casos de listerioses, devido a contaminação cruzada (DAVIES; BOARD, 1998; BARBUT, 2002; FRANCO; LANDGRAF, 2005).

A pesquisa de Staphylococcus spp. fundamentou-se no fato deste microrganismo estar envolvido em inúmeros casos de toxinfecção alimentar (PORTO et al., 2000) e também como indicador de higiene. Os estafilococos são amplamente difundidos na natureza e fazem parte da microbiota normal da pele e mucosas de mamíferos e aves, sendo que o principal reservatório, no homem, são as fossas nasais. Assim, os fatores que mais predispõem à contaminação vêm da inadequada manipulação dos produtos, resultando em contaminação cruzada na exposição dos produtos a temperaturas adequadas ao crescimento bacteriano (MESQUITA et al., 2006).

A legislação vigente no Brasil não estabelece padrão para S. aureus em carne de frango, no entanto, há relatos de que são necessárias entre $10^{5}$ e $10^{6}$ unidades formadoras de colônias de $S$. aureus por grama de alimento para que a toxina seja formada em níveis capazes de provocar intoxicação (BARBUT, 2002; LINDQVIST et al., 2002; FRANCO; LANDGRAF, 2005). Considerando-se este padrão e analisando-se a curva de crescimento (Figura 1), pode-se dizer que até 12 dias de armazenamento a $4^{\circ} \mathrm{C}$ o PS se apresentou em condições seguras para o consumo, em relação a este microrganismo. Porto et al. (2000) obtiveram resultados de Staphylococcus aureus menores que $2 \log _{10}$ UFC. $\mathrm{g}^{-1}$ de peito de frango marinado ( $4 \%$ de sal) nos tempos 0,6 e 11 dias de armazenamento a $5^{\circ} \mathrm{C}$. Vale ressaltar que no presente trabalho foi contado o número de unidades formadoras de colônias do gênero Staphylococcus spp., sem especificar a espécie.

Normalmente, estafilococos são encontrados em números baixos nos alimentos (FRANCO; LANDGRAF, 2005), o que se

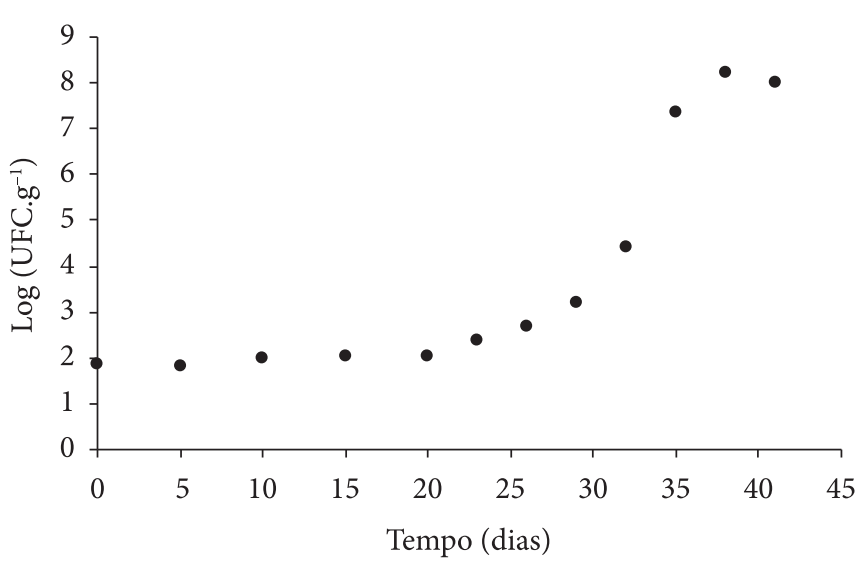

Figura 1. Curva de crescimento de Staphylococcus spp. determinada para filé de peito de frango temperado com $\mathrm{NaCl}$ armazenado a $-18 \pm 0,5^{\circ} \mathrm{C}$, por 20 dias, e transferido para armazenamento a $4 \pm 1{ }^{\circ} \mathrm{C}$, por mais 21 dias. verifica aqui, pois a contagem inicial foi de aproximadamente $2 \log _{10}$ UFC. $\mathrm{g}^{-1}$. Com uma velocidade máxima de crescimento $\left(\mu_{\text {max }}\right)$ de $0,058 \mathrm{~h}^{-1}$, a bactéria atingiu o seu valor mais alto, $8,2 \log _{10}$ UFC. $\mathrm{g}^{-1}$, aos 18 dias de armazenamento refrigerado a $4 \pm 0,5^{\circ} \mathrm{C}$.

Embora a contagem de microrganismos aeróbios psicrotróficos indique o grau de deterioração de alimentos refrigerados, a legislação brasileira não estabelece padrão para estes microrganismos. Entretanto, a International Commission on Microbiological Specificacions for Foods (1978) estabelece $10^{6}$ a $10^{7}$ UFC.g ${ }^{-1}$ como padrão, faixa seguida neste trabalho para definição do término da vida útil dos filés de frango. Outros autores estabelecem valores que variam de $10^{6}$ até $10^{8}$ UFC.g $^{-1}$ (HAYES, 1993; DAVIES; BOARD, 1998; SENTER; ARNOLD; CHEW, 2000; SMOLANDER et al., 2004; FRANCO; LANDGRAF, 2005; ORDÓÑEZ-PEREDA et al., 2005). A alteração da carne refrigerada em aerobiose é um fenômeno de superfície. Portanto, para definir uma carne alterada, geralmente se admitem os valores da taxa bacteriana de quando são detectadas as mudanças sensoriais devido aos metabólitos resultantes do crescimento microbiano (odores anômalos, normalmente desagradáveis, e aparecimento de substâncias viscosas, como polissacarídeos sintetizados pelas bactérias).

Assim, considerando estes padrões microbiológicos $\left(10^{6} \mathrm{a}\right.$ $10^{7} \mathrm{UFC}^{-1} \mathrm{~g}^{-1}$ ), o PI se manteve adequado para consumo até 9 a 11 dias a $4^{\circ} \mathrm{C}$, em relação aos psicrotróficos (Figura 2). Tal período é bastante extenso quando comparado ao de 5 a 6 dias reportado por Porto et al. (2000). Essa vantagem é esclarecida quando se comparam as contagens bacterianas iniciais. Neste estudo foi detectado o valor de 4,6 $\times 10^{3}$ UFC. $\mathrm{g}^{-1}$, enquanto os citados autores verificaram $5,4 \times 10^{4} \mathrm{UFC} \cdot \mathrm{g}^{-1} \mathrm{de}$ filé de peito de frango cru, no dia zero. É sabido que o tempo de vida útil das carnes possui uma relação inversa com a contaminação inicial do produto (DAVIES; BOARD, 1998; BARBUT, 2002; JAY, 2005).

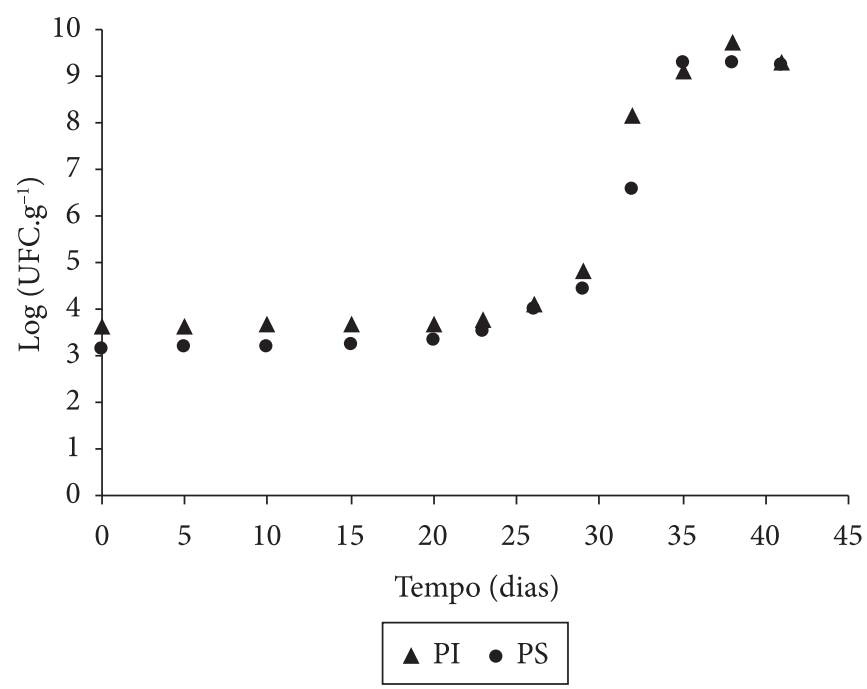

Figura 2. Curvas de crescimento de aeróbios psicrotróficos determinadas para filé de peito de frango cru (PI) e filé de peito de frango temperado com $\mathrm{NaCl}(\mathrm{PS})$ armazenados a $-18 \pm 0,5^{\circ} \mathrm{C}$, por 20 dias, e transferidos para armazenamento a $4 \pm 1^{\circ} \mathrm{C}$, por mais 21 dias. PI: Filé de peito de frango cru; PS: Filé de peito de frango temperado com $\mathrm{NaCl}$. 
O filé de peito de frango temperado com $\mathrm{NaCl}$ (PS) analisado apresentou um período de vida útil de 11 a 13 dias quando armazenado a $4{ }^{\circ} \mathrm{C}$. O PS teve maior durabilidade que PI, pois a contagem inicial de PI $\left.\left(4,6 \times 10^{3} \mathrm{UFC}^{-1}\right)^{-1}\right)$ foi maior que PS $\left(2,2 \times 10^{3} \mathrm{UFC}^{-1} \mathrm{~g}^{-1}\right)$, e no substrato de PS as bactérias psicrotróficas tiveram menor velocidade específica máxima de crescimento $\left(\mu_{\text {máx }} \mathrm{PS}=0,057 \mathrm{~h}^{-1}\right.$ e $\left.\mu_{\text {máx }} \mathrm{PI}=0,058 \mathrm{~h}^{-1}\right)$. Isto, talvez, em virtude do cloreto de sódio presente em PS, que, embora em baixo teor, pode ter exercido leve ação antimicrobiana (GUAJARDO; JARAMILLO, 1995). Na literatura se verifica que filé de peito de frango marinado ( $4 \%$ de sal) apresentou contagem de $1,0 \times 10^{7}$ UFC. $\mathrm{g}^{-1}$, após 6 dias de armazenamento a $5^{\circ} \mathrm{C}$. Neste caso, também é possível justificar a maior vida útil do PS em relação a este estudo comparando-se as contagens iniciais de ambos os casos, em que PS teve contaminação de $2,2 \times 10^{3}$ UFC.g ${ }^{-1}$, enquanto o marinado apresentou $1,4 \times 10^{4} \mathrm{UFC}$. ${ }^{-1}$. Além disso, a temperatura de incubação do marinado foi de $5{ }^{\circ} \mathrm{C}$, enquanto que PS foi mantido a $4{ }^{\circ} \mathrm{C}$ (PORTO et al., 2000).

É estabelecida a contagem de aeróbios mesófilos de $10^{7}$ UFC. $g^{-1}$ como indicador para o fim da vida útil (INTERNATIONAL...,1986). Estudos consideram fora das condições higiênico-sanitárias ideais os frangos que ultrapassam a contagem de mesófilos $10^{6} \mathrm{UFC}^{-1}{ }^{-1}$ (RITTER; BERGMANN, 2003). Baseado nestes padrões, no presente trabalho a faixa de contagem entre $10^{6}$ e $10^{7}$ UFC.g ${ }^{-1}$ foi considerada limite máximo para determinação da vida útil.

Pela análise do gráfico de crescimento de aeróbios mesófilos (Figura 3), verifica-se que as amostras de PI e PS se mantiveram dentro dos padrões de qualidade até a faixa de 12 a 13 dias e de 13 a 14 dias de armazenamento refrigerado, respectivamente. As curvas, praticamente sobrepostas, demonstram o semelhante comportamento dos mesófilos em ambos os substratos. Com uma velocidade específica máxima de crescimento ligeiramente maior, PI apresentou um salto no dia $12\left(\mu_{\text {max }}\right.$ PS $=0,055 \mathrm{~h}^{-1}$

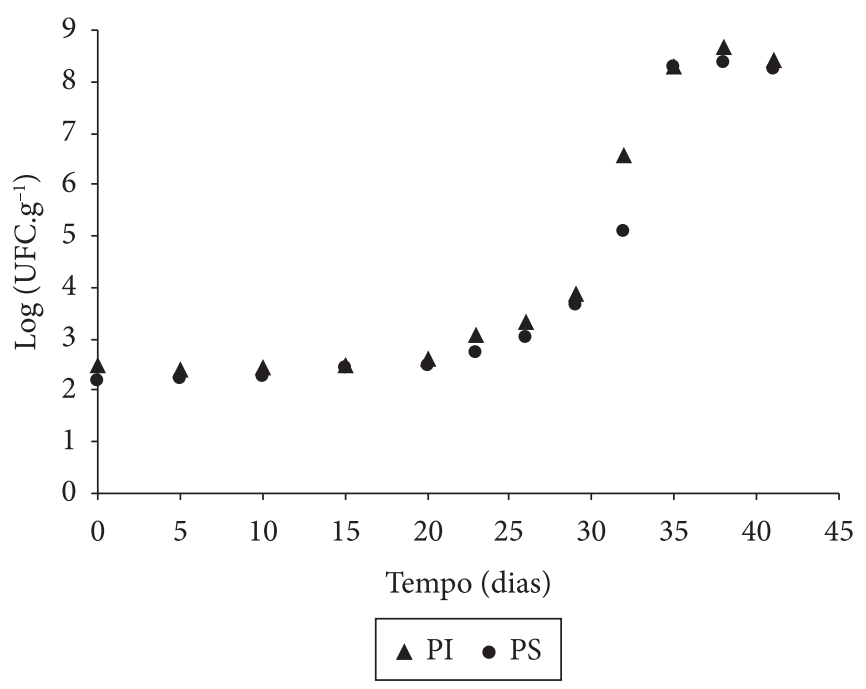

Figura 3. Curvas de crescimento de aeróbios mesófilos determinadas para filé de peito de frango cru (PI) e filé de peito de frango temperado com $\mathrm{NaCl}$ (PS) armazenados a $-18 \pm 0,5^{\circ} \mathrm{C}$, por 20 dias, e transferidos para armazenamento a $4 \pm 1{ }^{\circ} \mathrm{C}$, por mais 21 dias. PI: Filé de peito de frango cru; PS: Filé de peito de frango temperado com $\mathrm{NaCl}$. e $\mu_{\text {máx }}$ PI $\left.=0,056 \mathrm{~h}^{-1}\right)$. Em frangos resfriados, a contagem de microrganismos aeróbios mesófilos indica as condições de higiene no processo do frango, pois estes microrganismos são aqueles que vêm aderidos às penas, pele, pés e cloaca. Durante o abate das aves, juntam-se a esses microrganismos, aqueles presentes no sistema digestivo, quando o processo tecnológico não é realizado adequadamente (RITTER; BERGMANN, 2003).

No presente estudo, as fases lag de crescimento dos mesófilos e psicrotróficos em PI e PS ocorreram até o $6^{\circ}$ dia de armazenamento refrigerado. As máximas contagens de aeróbios mesófilos e psicrotróficos foram atingidas após 15 dias de armazenamento, tanto para PI como PS, ultrapassando contagens de $8 \log$ UFC. ${ }^{-1}$. Com apenas 11 dias sob refrigeração, Porto et al. (2000) encontraram 5,0 $\times 10^{9}$ UFC de psicrotróficos por grama de filé marinado. Smolander et al. (2004) avaliaram cortes de frango armazenados em diferentes temperaturas, que variaram de 3,4 a $8,3{ }^{\circ} \mathrm{C}$. Em seus estudos, as contagens de aeróbios mesófilos e psicrotróficos atingiram o máximo de $8 \log \mathrm{UFC}^{-g^{-1}}$ após 9 dias de estocagem, na maioria dos casos. Após este tempo, o nível dos microrganismos se manteve estável, indicando a fase estacionária de crescimento microbiano, semelhantemente ao aqui verificado.

Fazendo-se uma comparação entre as contagens de aeróbios mesófilos e psicrotróficos, se observa que a contagem de psicrotróficos em PI e PS se mostra superior, cerca de um ciclo logarítmico, aos valores determinados em mesófilos. Em seus experimentos, Smolander et al. (2004) não observaram diferença entre as contagens de aeróbios mesófilos e psicrotróficos em cortes de frangos armazenados em diferentes temperaturas, que variaram de 3,4 a $8,3{ }^{\circ} \mathrm{C}$. A exceção foi no armazenamento a $3,4^{\circ} \mathrm{C}$ (valor médio) em que, após 9 dias, houve um considerável aumento na contagem de aeróbios mesófilos.

Aeróbios totais e Pseudomonas spp. são bons indicadores de deterioração de carne de aves (DOMINGUEZ; SCHAFFNER, 2007). A contagem de Pseudomonas spp. definida como indicativa de término de vida útil é de 6 a $7 \log _{10}$ UFC. g $^{-1}$ (THORNLEY; INGRAM; BARNES, 1960; COX et al., 1975; ALLEN; RUSSELL; FLETCHER, 1997; MEHYAR et al., 2005). Assim, as amostras de PC, PI e PS se mantiveram apropriadas para consumo até 11 a 12 dias de armazenamento a $4{ }^{\circ} \mathrm{C}$ (Figura 4).

Pela análise da Figura 4 se verifica que a fase lag de crescimento ocorreu até o $6^{\circ}$ dia de armazenamento refrigerado a $4 \pm 0,5^{\circ} \mathrm{C}$ nas três amostras. Também se observa que PS foi a amostra que apresentou menor valor de máxima contagem, $7 \log _{10}$ UFC. $\mathrm{g}^{-1}$, ao passo que PI e PC atingiram em torno de $9 \log _{10}$ UFC. $\mathrm{g}^{-1}$. É possível explicar tal efeito pelo fato de que a adição de sal ao produto atua como agente antimicrobiano (GUAJARDO; JARAMILLO,1995; BARBUT, 2002). Os valores determinados de velocidade específica máxima de crescimento das bactérias do gênero Pseudomonas nas três amostras revelam seu comportamento variado nos diferentes substratos, onde $\mu_{\text {máx }}$ $\mathrm{PC}=0,079 \mathrm{~h}^{-1} ; \mu_{\text {máx }} \mathrm{PI}=0,065 \mathrm{~h}^{-1}$ e $\mu_{\text {máx }} \mathrm{PS}=0,053 \mathrm{~h}^{-1}$. 


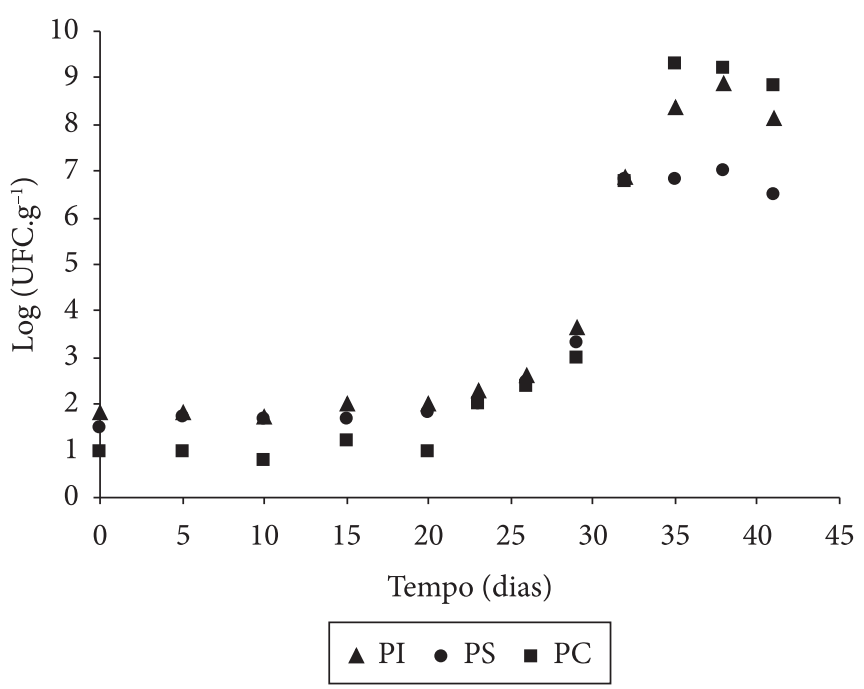

Figura 4. Curvas de crescimento de Pseudomonas spp. determinadas para filé de peito de frango cru (PI), filé de peito de frango temperado com $\mathrm{NaCl}$ (PS) e filé de peito de frango cozido armazenados a $-18 \pm 0,5^{\circ} \mathrm{C}$, por 20 dias, e transferidos para armazenamento a $4 \pm 1{ }^{\circ} \mathrm{C}$, por mais 21 dias. PI: Filé de peito de frango cru; PS: Filé de peito de frango temperado com NaCl; PC: Filé de peito de frango cozido.

\section{Conclusões}

A presença de Salmonella spp. e Listeria monocytogenes não foi detectada nos produtos analisados nas condições estudadas, indicando boas condições de higiene e segurança dos produtos. Durante os 20 dias da fase congelada $\left(-18 \pm 0,5^{\circ} \mathrm{C}\right)$, a presença de aeróbios mesófilos e psicrotróficos, Pseudomonas spp. e Staphylococcus spp. se manteve estável em baixos níveis de detecção. Depois de descongelados e mantidos a $4 \pm 0,5{ }^{\circ} \mathrm{C}$, 9 dias para filé de peito de frango cru (PI), 11 dias para filé de peito de frango cozido (PC) e 11 dias para filé de peito de frango temperado com $\mathrm{NaCl}$ (PS) mostraram ser o tempo limite para garantir a qualidade, considerando os microrganismos pesquisados em cada tipo de produto.

\section{Agradecimentos}

Os autores agradecem ao Projeto Chill-On (Comissão Europeia, FP6-2006-Food-3-A, FOOD-CT-2006-016333) o financiamento da pesquisa e à Coordenação de Aperfeiçoamento de Pessoal de Nível Superior (CAPES) a bolsa de pesquisa.

\section{Referências bibliográficas}

ALLEN, C. D.; RUSSELL, S. M.; FLETCHER, D. L. The relationship of broiler breast meat color and ph to shelf life and odor development. Poultry Science, v. 76, p. 1042-1046, 1997.

BARBUT, S. Poultry products processing: an industry guide. Boca Raton: CRC, 2002. 548 p.

BRASIL. Ministério da Agricultura, do Abastecimento e da Reforma Agrária. Instrução Normativa 62, de 26 de agosto de 2003. Métodos analíticos oficiais para análises microbiológicas para o controle de produtos de origem animal e água. Diário Oficial [da] República Federativa do Brasil, Poder Executivo, Brasília, DF, 18 de set. 2003. Seção I.
BRYAN, F. L. Risks of pratices ans processes that lead to outbreaks of food-borne diseases. Journal of Food Protection, v. 51, n. 8, p. 663-673, 1998.

CANSIAN, R. L.; FLORIANI, S. T. R.; VALDUGA, E. Microbiological analysis of critical points in the chicken industry. Brazilian Archives of Biology and Technology, v. 48, n. 3, p. 403-406, 2005.

COX, N. A. et al. Spoilage odors in poultry meat produced by pigmented and nonpigmented Pseudomonas. Poultry Science, v. 54, p. 2001-2006, 1975.

DAVIES, A.; BOARD, R. The microbiology of meat and poultry. London: Blackie Academic \& Professional, 1998. 346 p.

DOMINGUEZ, S. A.; SCHAFFNER, D. W. Development and validation of a mathematical model to describe the growth of Pseudomonas spp. in raw poultry stored under aerobic conditions. International Journal of Food Microbiology, v. 120, p. 287-295, 2007.

FARBER, J. M.; PETERKIN, P. I. Listeria monocytogenes, a foodborne pathogen. Microbiological Reviews, v. 55, p. 476-511, 1991.

FENNEMA, O. R. Química de los alimentos. 2. ed. Zaragoza: Acribia, 1992. $1095 \mathrm{p}$.

FLETCHER, D. L.; QIAO, M.; SMITH, D. P. The relationship of raw broiler breast meat color and ph to cooked meat color and $\mathrm{pH}$. Poultry Science, v. 79, p. 784-788, 2000.

FRANCO, B. D. G. M.; LANDGRAF, M. Microbiologia dos alimentos. São Paulo: Atheneu, 2005. 182 p.

FRONING, G. W.; SACKETT, B. Effect of salt and phosphates during tumbling of turkey breast muscle on meat characteristics. Journal of Poultry Sience, v. 64, p. 1328-1333, 1985.

GONÇALVES, P. M. R. Toxinfecções alimentares: uma revisão. Higiene Alimentar, v.12, n. 53, p. 38-44, 1998.

GUAJARDO, E. R.; JARAMILLO, H. G. El marinado: una opción rentable en la carne de bovino. Carnetec, v. 2, n. 5, p. 2024, 1995.

HAYES, P. R. Microbiología e higiene de los alimentos. Zaragoza: Acribia, 1993. 369 p.

INTERNATIONAL COMMISSION ON MICROBIOLOGICAL SPECIFICATIONS FOR FOODS - ICMSF. Microorganisms in foods: their significance and methods of enumeration. Toronto: University of Toronto, 1978.

INTERNATIONAL COMMISSION ON MICROBIOLOGICAL SPECIFICATIONS FOR FOODS - ICMSF. Microorganisms in Foods. Sampling for Microbiological Analysis: Principles and Scientific Applications. Toronto: University of Toronto, 1986. v. 2, p. 181-186.

JAY, J. M. Microbiologia de alimentos. 6. ed. Porto Alegre: Artmed, 2005.

KINSELLA, J. E. et al. Sterol, phospholipid, mineral content and proximate composition of fillets of select freshwater fish species. Journal of Food Biochemistry, v. 1, n. 2, p. 131-140, 1977.

LINDQVIST, R.; SYLVÉN, S.; VAGSHOLM, I. Quantitative microbial risk assessment exemplified by Staphylococcus aureus in unripened cheese made from raw milk. International Journal of Food Microbiology, v. 78, p. 155-170, 2002.

MAIA, E. L.; RODRIGUEZ-AMAYA, D. B. Fatty acid composition of the total, neutral and phospholipids of the Brazilian freshwater fish Colossoma macropomum. In: CHARALAMBOUS, G. (Ed.). Food Science and Human Nutrition. Amsterdam: Elsevier Science, 1992. p. 633-642.

MAIA, E. L.; RODRIGUEZ-AMAYA, D. B.; FRANCO, M. R. B. Fatty acids of the total, neutral and phospholipids of the Brazilian 
freshwater fish Prochilodus scrofa. Journal of Food Composition and Analysis, v. 7, p. 240-251, 1994.

MEAD, G. C. Hygienic problems and control of process contamination. In: MEAD, G. C. Processing of poultry. New York: Elsevier, 1989. p. 360-368.

MEHYAR, G. et al. Effectiveness of trisodium phosphate, lactic acid and commercial antimicrobials against pathogenic bacteria on chicken skin. Food Protection Trends, v. 25, p. 351-362, 2005.

MESQUITA, M. O. et al. Qualidade microbiológica no processamento do frango assado em unidade de alimentação e nutrição. Ciência e Tecnologia de Alimentos, v. 26, n. 1, p. 198-203, 2006.

MURIANA, P. M. Bacteriocins for control of Listeria spp. in food. Journal Food Protection, v. 59, p. 54-63, 1996.

NUNES, T. P. Efeito da pré-cura na estabilidade microbiológica da carne mecanicamente separada e elaboração de um produto reestruturado com filés de peito de galinhas de descarte. 2003. 101 f. Dissertação (Mestrado em Ciências)-Escola Superior de Agricultura Luiz de Queiroz, Universidade de São Paulo, Piracicaba, 2003.

OLIVEIRA, S. L. C. L. Estudo dos constituintes lipídicos em peixes do Ceará. 1999. 118 f. Dissertação (Mestrado em Engenharia de Pesca)-Universidade Federal do Ceará, Fortaleza, 1999.

ORDÓÑEZ-PEREDA, J. A. et al. Tecnologia de alimentos - Alimentos de origem animal. Trad. MURAD, F. Porto Alegre: Artmed, 2005. v. 2.

PARDI, M. C. et al. Ciência, higiene e tecnologia da carne: riscos microbiológicos da carne. Goiânia: UFG, 1995. v. 1, p. 294-308.

PELISSER, M. R. et al. Detection of Listeria species in refrigerated chicken carcasses using Clearview ${ }^{\mathrm{TM}}$ and a modified conventional culture method. Brazilian Journal of Microbiology, v. 32, p. 113-116, 2001.

PINI, P. N.; GILBERT, R. J. The occurrence in the U.K. of Listeria species in raw chickens and soft cheeses. International Journal of Food Protection, v. 56, n. 7, p. 616-618, 1993.

PORTO, A. C. S. et al. Influência da composição da salmoura sobre os parâmetros físico sensoriais e microbiológicos de filés de peito de frango marinados por imersão. Boletim Ceppa, v. 18, n. 2, p. 141150, 2000.

RITTER, R.; BERGMANN, G. P. Eficácia do sistema de pré-resfriamento de frangos em tanques, sobre a redução da contaminação bacteriana de carcaças. Higiene alimentar, v. 17, n. 108, p. 97-104, 2003.

ROÇA, R. O. Composição química da carne. Disponível em: <http:// pucrs.campus2.br/ thompson/TPOA-Carne/Roca102.pdf $>$. Acesso em: 16 jan. 2008.

RYSER, E. T.; MARTH, E. H. Listeria, Listeriosis, and Food Safety. New York: University of Wisconsin, 1991, 632 p.

SCHWAB, J. P.; EDELWEISS, M. I. A. Identification of Listeria monocytogenes in human placentas and abortion species through immunohistochemical technique. Jornal Brasileiro de Patologia e Medicina Laboratorial, Rio de Janeiro, v. 39, n. 2, p. 111-114, 2003.

SENTER, S. D.; ARNOLD, J. W.; CHEW, V. APC values and volatile compounds formed in commercially processed, raw chicken parts during storage at 4 and $13{ }^{\circ} \mathrm{C}$ and under simulated temperature abuse conditions. Journal of the Science of Food and Agriculture, v. 80 , p. $1559-1564,2000$.

SILVA JUNIOR, E. A. S. Manual de controle higiênico sanitário em alimentos. 4. ed. São Paulo: Varela, 2001. 475 p.

SMOLANDER, M. et al. Monitoring of the quality of modified atmosphere packaged broiler chicken cuts stored in different temperature conditions. A. Time-temperature indicators as qualityindicating tools. Food Control, v. 15, p. 217-229, 2004.

STANBRIDGE, L. H.; BOARD, R. G. A modification of the Pseudomonas selective medium, CFC, that allows differentiation between meat Pseudomonas and Enterobacteriaceae. Letters in Applied Microbiology, v. 18, p. 327-328, 1994.

THORNLEY, M. J.; INGRAM, M.; BARNES, E. M. The effects of antibiotics and irradiation on the Pseudomonas-Achromobacter flora of chilled poultry. Journal of Applied Bacteriology, v. 23, p. 487-498, 1960.

UBOLDI-EIROA, M. N. Listeria monocytogenes - Características, ocorrência e desenvolvimento em alimentos. Coletânea do Instituto de Tecnologia de Alimentos, v. 20, n. 1, p. 13-22, 1990.

UNIÃO BRASILEIRA DE AVICULTURA - UBA. Relatório anual 2006/2007. Disponível em: <http://www.uba.org.br >. Acesso em: 02 jan. 2008.

UNIÃO EUROPÉIA. Regulation (EC) no 178/2002 of the European Parliament and of the Council of 28 January 2002. Laying down the general principles and requirements of food law, establishing the European Food Safety Authority and laying down procedures in matters of food safety. 2002.

UYTTENDALE, M. R. et al. Incidence of Listeria monocytogenes in poultry and poultry products obtained from Belgian and French abbatoirs. Food Microbiology, v. 14, n. 4, p. 339-345, 1997.

VALERIANO, C. et al. Avaliação higiênico-sanitária de miúdos de frango comercializados na cidade de Lavras- MG. Higiene Alimentar, v.17, n. 104/105, p. 214-215, 2003.

VARNAM, A. H.; SUTHERLAND, J. P. Meat and meat products: technology, chemistry and microbiology. London: Chapman \& Hall, 1995. v. 3, 444 p.

VENTURINI, K. S.; SARCINELLI, M. F.; SILVA, L. C.. Boletim Técnico - PIE-UFES:01307. 18 ago. 2007. Disponível em: <http:// www.agais.com/telomc/b01307_caracteristicas_carnefrango.pdf $>$. Acesso em: 15 fev. 2008.

VIEIRA, J. O. et al. Efeito dos métodos de cocção na composição centesimal e colesterol do peito de frangos de diferentes linhagens. Ciência e Agrotecnologia, v. 31, n. 1, p. 164-170, 2007. 